\title{
Potentiometric flow injection sensing system for determination of heparin based on current-controlled release of protamine
}

\author{
Jiahong Lei ${ }^{\mathrm{a}, \mathrm{b}, 1}$, Jiawang Ding ${ }^{\mathrm{a}, \mathrm{b}, 1}$, Yan Chen ${ }^{\mathrm{a}}$, Wei Qin ${ }^{\mathrm{a}, *}$ \\ ${ }^{a}$ Key Laboratory of Coastal Environmental Processes and Ecological Remediation, Yantai Institute of Coastal Zone Research (YIC), Chinese Academy of Sciences \\ (CAS), Shandong Provincial Key Laboratory of Coastal Environmental Processes, YICCAS, Yantai, Shandong 264003, PR China \\ ${ }^{\mathrm{b}}$ University of Chinese Academy of Sciences, Beijing 100049, PR China
}

\section{H I G H L I G H T S}

- A potentiometric flow injection system for determination of heparin is described.

- An external current is applied for controlled release of protamine.

- The system has been employed for detection of heparin in whole blood.

\section{A R T I C L E IN F O}

\section{Article history:}

Received 26 September 2014

Received in revised form 4 December 2014

Accepted 9 December 2014

Available online 11 December 2014

\section{Keywords:}

Potentiometry

Polycation-sensitive membrane electrodes Protamine

Heparin

Current-controlled release

Flow injection analysis
G R A P H I C A L A B S T R A C T

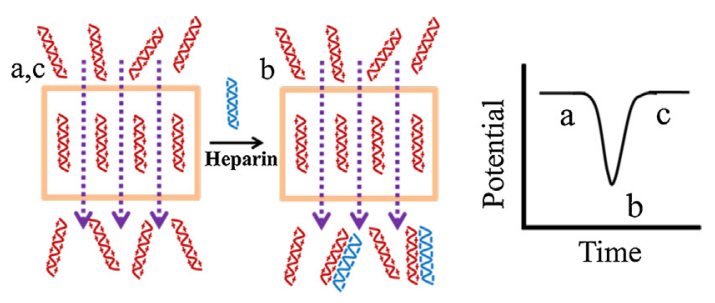

$\ldots . . .>$ Current $\square$ Polymeric Membrane

\begin{abstract}
A B S T R A C T
A flow injection system incorporated with a polycation-sensitive polymeric membrane electrode in the flow cell is proposed for potentiometric determination of heparin. An external current in nano-ampere scale is continuously applied across the polymeric membrane for controlled release of protamine from the inner filling solution to the sample solution, which makes the electrode membrane regenerate quickly after each measurement. The protamine released at membrane-sample interface is consumed by heparin injected into the flow cell via their strong electrostatic interaction, thus decreasing the measured potential, by which heparin can be detected. Under optimized conditions, a linear relationship between the potential peak height and the concentration of heparin in the sample solution can be obtained in the range of $0.1-2.0 \mathrm{U} \mathrm{mL}^{-1}$, and the detection limit is $0.06 \mathrm{U} \mathrm{mL}^{-1}$. The proposed potentiometric sensing system has been successfully applied to the determination of heparin in undiluted sheep whole blood.
\end{abstract}

(c) 2014 Elsevier B.V. All rights reserved.

\section{Introduction}

Heparin is a highly-sulfated polysaccharide with an average molecular weight of 15,000 and an average valence of 70 . It is widely used as an anticoagulant drug in a variety of surgical procedures, such as kidney dialysis and open heart surgery, via the accelerating effect on inactivating coagulation factors [1,2]. Rapid

\footnotetext{
* Corresponding authorTel.: +86 535 2109156; fax: +86 5352109000 E-mail address: wqin@yic.ac.cn (W. Qin).

1 The two authors contributed equally to this work.
}

and accurate measurement of heparin levels during clinical procedures are of crucial importance to avoid significant detrimental effects caused by heparin overdosing, such as hemorrhages and thrombocytopenia $[3,4]$.

The activated clotting time (ACT) or the activated partialthromboplastin time (aPTT) has been widely used for the quantification of heparin in clinical analysis. However, these assays are indirect and not always reliable [5]. Various methods including colorimetry [6], Raman spectroscopy [7,8], liquid chromatography [9], electrochemistry [10], and fluorimetry [11] have also been developed for measuring heparin. Unfortunately, these methods may not be suitable for whole blood analysis. In 
recent years, potentiometric sensors based on polyion-sensitive membranes have made significant contributions to heparin quantification, even in undiluted blood, via direct [12-15] or indirect [16-20] detection modes. Since the spontaneous extraction of polyions into membrane phase can form cooperative ion pairs with the lipophilic ion exchangers in the membranes, it is unfortunate that these electrodes are naturally irreversible $[14,15,21]$. More recently, reversible polyion-sensitive membrane electrodes based on the chronopotentiometric sensing strategy have been developed [22-26]. In this method, a lipophilic salt with a carefully matched cation and anion is added into the polymeric membrane to suppress the spontaneous extraction of polyions and a current pulse is applied to control the cation or anion fluxes into the membrane. This method can also be used for on-line rapid determination of heparin via flow injection analysis (FIA) [27]. However, the determination of heparin could be disturbed by the lipophilic anions co-existing in samples.

Recently, we developed a polycation-sensitive membrane electrode for reagentless determination of heparin by using the zero current ion fluxes of protamine released from the inner filling solution to the sample solution [28]. The electrode can be reused by conditioning at a high concentration of protamine for ca. $10 \mathrm{~min}$ before next measurement. Such an additional regeneration procedure will prolong the analysis time and make continuous monitoring difficult. In the present work, an external anodic current is continuously applied across the polymeric membrane to drive the ion fluxes of protamine from the inner filling solution to the sample solution, which could make the electrode membrane regenerate quickly after each measurement. By integrating the FIA and galvanostatic techniques, a rapid and continuous sensing platform for heparin has been constructed. As shown in Fig. 1a, the applied current drives the fluxes of protamine through the polycation-sensitive membrane with a stable potential baseline. When heparin is injected into the flow cell with the carrier solution, it can electrostatically bind to protamine released at the sample-membrane interface. The consumption of free protamine could facilitate the stripping of protamine out of the membrane surface via the ion-exchange process with sodium ions, thus decreasing the membrane potential (Fig. 1b) [28]. With the current-controlled reagent delivery, the membrane electrode can be regenerated on line shortly after heparin flows out of the flow cell, which allows continuous sensing of heparin in the flow injection mode (Fig. 1c).

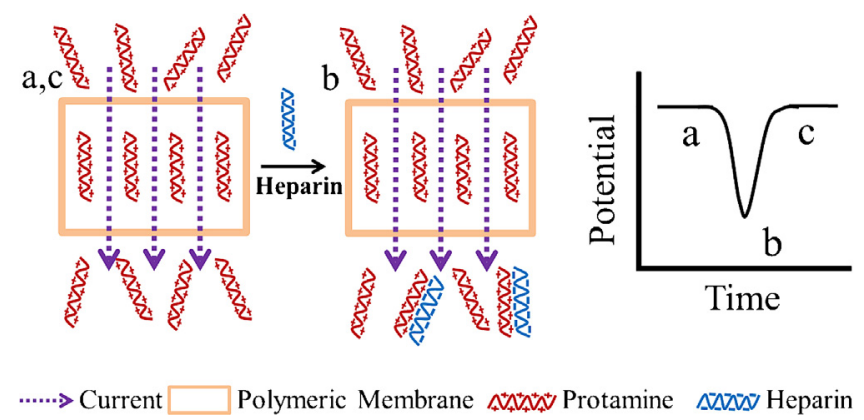

Fig. 1. Illustration of potentiometric flow injection determination of heparin with a polycation-sensitive membrane electrode based on the current-controlled release of protamine from the inner filling solution to the sample solution: (a) potential baseline (without heparin); (b) sample injection (with heparin); (c) membrane recovery (without heparin).

\section{Experimental}

\subsection{Reagents}

Dinonylnaphthalene sulfonic acid (DNNS) as a $50 \%$ solution in heptane, protamine sulfate from herring, heparin sodium salt from bovine intestinal mucosa (198 $\mathrm{U} \mathrm{mg}^{-1}$ ), Trizma base (Tris) were purchased from Sigma-Aldrich (St. Louis, MO, USA). High molecular weight poly(vinyl chloride) (PVC), 2-nitrophenyl octyl ether (o-NPOE) and tetradodecylammonium tetrakis(4-chlorophenyl) borate (ETH 500) were purchased from Fluka AG (Buchs, Switzerland). All the chemicals were of selectophore or analytical grade. Aqueous solution was prepared with freshly deionized water (18.2 $\mathrm{M} \Omega \mathrm{cm}^{-1}$ specific resistance) obtained with a Pall Cascada laboratory water system. Unless stated otherwise, $0.05 \mathrm{~mol} \mathrm{~L}^{-1}$ Tris- $\mathrm{HCl}$ buffer ( $\mathrm{pH} 7.4$ ) containing $0.12 \mathrm{~mol} \mathrm{~L}^{-1} \mathrm{NaCl}$ was used as sample medium and carrier solution.

\subsection{Apparatus}

The FIA system for determination of heparin was controlled by a flow injection analyzer (FIS-D, Xi'an Remex Analyze Instrument Co., Ltd., China). The system contains two peristaltic pumps $\left(1.8 \mathrm{~mL} \mathrm{~min}^{-1}\right)$, a six-way injection valve (500 $\mu \mathrm{L}$ loop) and a walljet flow cell $(60 \mu \mathrm{L})$ [29]. The detection chamber has a threeelectrode system. The working electrode (polycation-sensitive membrane electrode, i.d. $4 \mathrm{~mm}$, o.d. $6 \mathrm{~mm}$ ) and the reference electrode $(\mathrm{Ag} / \mathrm{AgCl}$ electrode with an inner filling solution of $3 \mathrm{~mol} \mathrm{~L}^{-1} \mathrm{KCl}$, i.d. $2 \mathrm{~mm}$, o.d. $4 \mathrm{~mm}$ ) were embedded in the cell body, with a distance of $10 \mathrm{~mm}$. A platinum wire as the counter electrode was placed between the working and the reference electrodes. Tygon and PTFE tubes were used to assemble the flowthrough system. A CHI-660C electrochemical workstation (Shanghai Chenhua Apparatus Corporation, China) was used to perform potentiometric measurements.

\subsection{Membranes and electrode preparation}

The polycation-sensitive membranes contained $3 \mathrm{wt} \%$ DNNS, $6 \mathrm{wt} \%$ ETH 500, $30 \mathrm{wt} \%$ PVC and $61 \mathrm{wt} \%$ o-NPOE. The membranes $(\sim 100 \mu \mathrm{m})$ were obtained by casting a membrane cocktail $(386 \mathrm{mg}$ ) dissolved in $6.0 \mathrm{~mL}$ THF into a glass ring of $50 \mathrm{~mm}$ diameter fixed on a glass plate and evaporating the solvent overnight. Disks of $6 \mathrm{~mm}$ diameter punched from the parent membrane were glued to plasticized PVC tubes (i.d. $4 \mathrm{~mm}$, o.d. $6 \mathrm{~mm}$ ) to fabricate the polycation-sensitive membrane electrodes. $0.05 \mathrm{mg} \mathrm{mL}^{-1}$ protamine in $1 \mathrm{~mL}$ of $0.05 \mathrm{~mol} \mathrm{~L}^{-1}$ Tris- $\mathrm{HCl}$ buffer ( $\mathrm{pH} 7.4$ ) containing $0.12 \mathrm{~mol} \mathrm{~L}^{-1} \mathrm{NaCl}$ was used as the inner filling solution. During the polarization, a stable potential on the inner side of the membrane can be obtained in the presence of a high concentration of sodium chloride. Before measurements, all the electrodes were conditioned in the solution identical to the inner filling solution for $12 \mathrm{~h}$ at $25 \pm 1{ }^{\circ} \mathrm{C}$, which ensures the stable ion fluxes of protamine from the inner solution to the sample solution.

\subsection{EMF measurements}

Ion-selective chronopotentiometry was used in this work. An anodic current of $20 \mathrm{nA}$ was applied across the polymeric membrane polycation-sensitive electrode to release protamine from the inner filling solution into the sample solution to get a stable baseline. Potentiometric measurements of the interactions of protamine with injected heparin at the membrane-sample interface were performed at room temperature in the galvanic cell: $\mathrm{Ag} / \mathrm{AgCl} / 3 \mathrm{~mol} \mathrm{~L}{ }^{-1} \mathrm{KCl} /$ sample solution/polycation-sensitive membrane/inner filling solution/AgCl/Ag. A $0.05 \mathrm{~mol} \mathrm{~L}^{-1} \mathrm{Tris}-\mathrm{HCl}$ buffer 
( $\mathrm{pH}$ 7.4) containing $0.12 \mathrm{~mol} \mathrm{~L}^{-1} \mathrm{NaCl}$ was used as the carrier solution for sample injection. The potential peak heights were used for heparin quantification.

\subsection{Real sample analysis}

The sheep blood samples were obtained from the local market. $0.01 \mathrm{~mol} \mathrm{~L}^{-1}$ citrate was added to the samples to prevent blood coagulation. Heparin was measured in spiked undiluted sheep blood samples with the potentiometric flow injection sensing system.

\section{Results and discussion}

\subsection{Current-controlled release of protamine for the FIA potentiometric sensing system}

The traditional protamine-sensitive membrane electrode can generate zero-current protamine ion fluxes from the membrane into the sample solution, which have been used for reagentless determination of heparin [28]. As shown in Fig. 2a, under zerocurrent conditions, a large potential decrease is observed in the presence of $1.0 \mathrm{U} \mathrm{mL}^{-1}$ heparin in the FIA system. However, the spontaneous release of protamine across the membrane to the sample solution cannot recover the membrane rapidly, thus inducing a large potential drift and a long recovery time. This effect may be due to the fact that the protamine molecules with high molecular weights need a rather long time to cross the membrane [13]. Recently, it has been found that the ion fluxes across the membrane can be modulated and controlled precisely by applying an external current [23,30-32]. Previous reports have shown that ions across the polymeric membrane ion-selective electrode can be selectively and precisely delivered to the sample solution for calibration-free titrations [33]. Recently, Crespo et al. developed a technique based on a thin layer Coulometry and revealed that protamine can be selectively transferred from a thin layer to the outer solution at a fixed applied potential [34]. In this work, an anodic current is continuously applied to promote the diffusion of protamine through the polymeric membrane and maintain a constant release of protamine across the membrane. As shown in Fig. 2b, a stable baseline as well as a short recovery time can be obtained in the FIA system with the current-controlled reagent delivery.

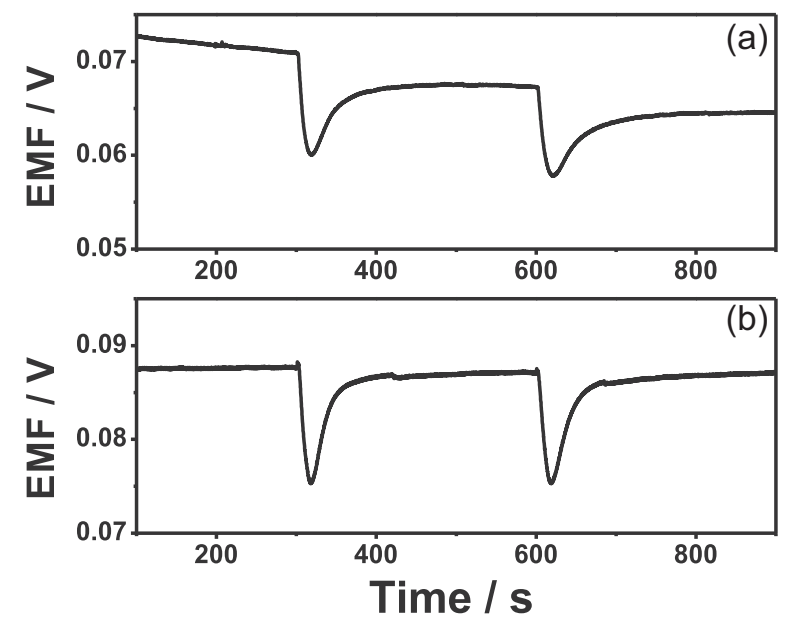

Fig. 2. Comparison of the potential responses of the polycation-sensitive membrane electrode in FIA system to $1.0 \mathrm{UmL}^{-1}$ heparin under zero-current conditions (a) and with an anodic current of $20 \mathrm{nA}$ (b). Unless stated otherwise, the following conditions were employed: membrane composition, $3 \mathrm{wt} \% \mathrm{DNNS} / 6 \mathrm{wt} \%$ ETH 500/31 wt\% PVC/60 wt\% o-NPOE; heparin, $1.0 \mathrm{U} \mathrm{mL}^{-1}$; carrier solution, $0.05 \mathrm{M}$ Tris-HCl buffer ( $\mathrm{pH} 7.4$ ) containing $0.12 \mathrm{M} \mathrm{NaCl}$; applied current, $20 \mathrm{nA}$; sample volume, $500 \mu \mathrm{L}$; flow rate, $1.8 \mathrm{~mL} \mathrm{~min}^{-1}$.

\subsection{Optimization of membrane components}

Since there is a sigmoidal relationship between the membrane potential and protamine concentration, the concentration of protamine released at membrane surface should be modulated in the most sensitive region so that a sensitive response curve can be obtained. The ratio of membrane components, which determines the diffusion coefficient and the cation-exchanger sites of protamine in the membrane phase, play an important role in controlling the concentration of protamine released at the membrane surface $[13,28]$. It is known that higher plasticizer contents increase the diffusion coefficient of protamine, and more anionic sits promote the ion-exchange process in the membrane phase. Both effects can facilitate the ion fluxes of protamine through the membrane, therefore increasing the concentration of protamine released at the membrane surface. In addition, higher lipophilic salt contents can also promote the diffusion of protamine by softening the membrane [21]. However, the membrane electrode may not be sensitive to heparin if too much protamine is released at the membrane surface (i.e., outside the most sensitive region). As shown in Table 1 , the membrane containing $3 \mathrm{wt} \%$ DNNS, $6 \mathrm{wt} \%$ ETH 500, $31 \mathrm{wt} \%$ PVC, and $60 \mathrm{wt} \% \mathrm{o}-\mathrm{NPOE}$ shows the best performance in the FIA potential response in terms of high sensitivity and wide linear range. Therefore, this membrane composition was selected for the present system.

\subsection{Optimization of FIA parameters}

The influence of applied current on the sensitivity of the polycation-sensitive electrode is shown in Fig. 3a. The peak height with a lower current of $10 \mathrm{nA}$ is higher than that with zero current, which is due to the increasing amount of protamine released at the membrane-sample interface. Higher currents can also lead to shorter recovery times. However, for currents higher than $20 \mathrm{nA}$, the concentration of protamine released at the membrane surface could be out of the most sensitive reaction region for measuring heparin, which decreases the potential peak heights. A current of $20 \mathrm{nA}$ was selected for sensitive determination of heparin and rapid recovery of the membrane electrode. The amount of protamine released per hour is negligible as compared to that in the inner filling solution (see Supporting information).

As shown in Fig. 3b, the potential response is correlated with the injected sample volume in the range of $100-500 \mu \mathrm{L}$. Heparin of larger sample volumes could consume more protamine released at the membrane-sample interface via the electrostatic interaction, thus causing larger potential changes. However, with an injected sample volume larger than $500 \mu \mathrm{L}$, the protamine consumption could not increase significantly, and the potential change would level off. Therefore, $500 \mu \mathrm{L}$ was used as the sample injection volume.

The effect of the flow rate on the potential response was investigated in the range of $0.9-2.8 \mathrm{~mL} \mathrm{~min}^{-1}$. As shown in Fig. $3 c$, the potential response to heparin increases with increasing the flow rate up to $1.8 \mathrm{~mL} \mathrm{~min}^{-1}$, which is probably due to the fact that more vigorous mixing in the flow cell could induce more efficient interaction between protamine and heparin. However, at flow rates higher than $1.8 \mathrm{~mL} \mathrm{~min}^{-1}$, the increase in flow rate would decrease the potential response, which might be attributed to the short duration for the protamine-heparin interaction in the flow cell. Therefore, the flow rate of $1.8 \mathrm{~mL} \mathrm{~min}^{-1}$ was chosen for the potentiometric FIA sensing system.

\subsection{Characteristics of the present potentiometric flow injection sensing system}

Under the optimal conditions, the potential response to heparin was tested for the FIA system. Since the consumed protamine at 
Table 1

Optimization of the membrane components of the polycation-sensitive electrode. ${ }^{\mathrm{a}}$

\begin{tabular}{|c|c|c|c|c|c|c|}
\hline PVC (wt\%) & $\begin{array}{l}\text { o-NPOE } \\
(\mathrm{wt} \%)\end{array}$ & $\begin{array}{l}\text { DNNS } \\
\text { (wt\%) }\end{array}$ & $\begin{array}{l}\text { ETH } 500 \\
(w t \%)\end{array}$ & $\begin{array}{l}\text { Linear range } \\
\left(\mathrm{U} \mathrm{mL}^{-1}\right)\end{array}$ & $\begin{array}{l}\text { Detection limit } \\
\left(\mathrm{UmL}^{-1}\right)\end{array}$ & $\begin{array}{l}\text { Slope } \\
\left(\mathrm{mVU}^{-1}\right)\end{array}$ \\
\hline 29.0 & 58.0 & 3.0 & 10.0 & $0.5-0.0$ & 0.09 & $3.0 \pm 0.2$ \\
\hline 31.0 & 60.0 & 3.0 & 6.0 & $0.1-2.0$ & 0.06 & $10.8 \pm 0.3$ \\
\hline 45.5 & 45.5 & 3.0 & 6.0 & $0.2-2.0$ & 0.16 & $9.4 \pm 0.7$ \\
\hline 31.0 & 62.0 & 1.0 & 6.0 & $0.5-2.0$ & 0.10 & $3.8 \pm 0.7$ \\
\hline 29.7 & 59.3 & 5.0 & 6.0 & $0.2-2.0$ & 0.19 & $9.0 \pm 0.1$ \\
\hline
\end{tabular}

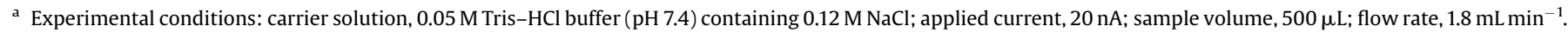

the membrane-sample interface can be replenished by the current-driven ion fluxes of protamine across the polycationsensitive membrane, the membrane electrode is recovered rapidly
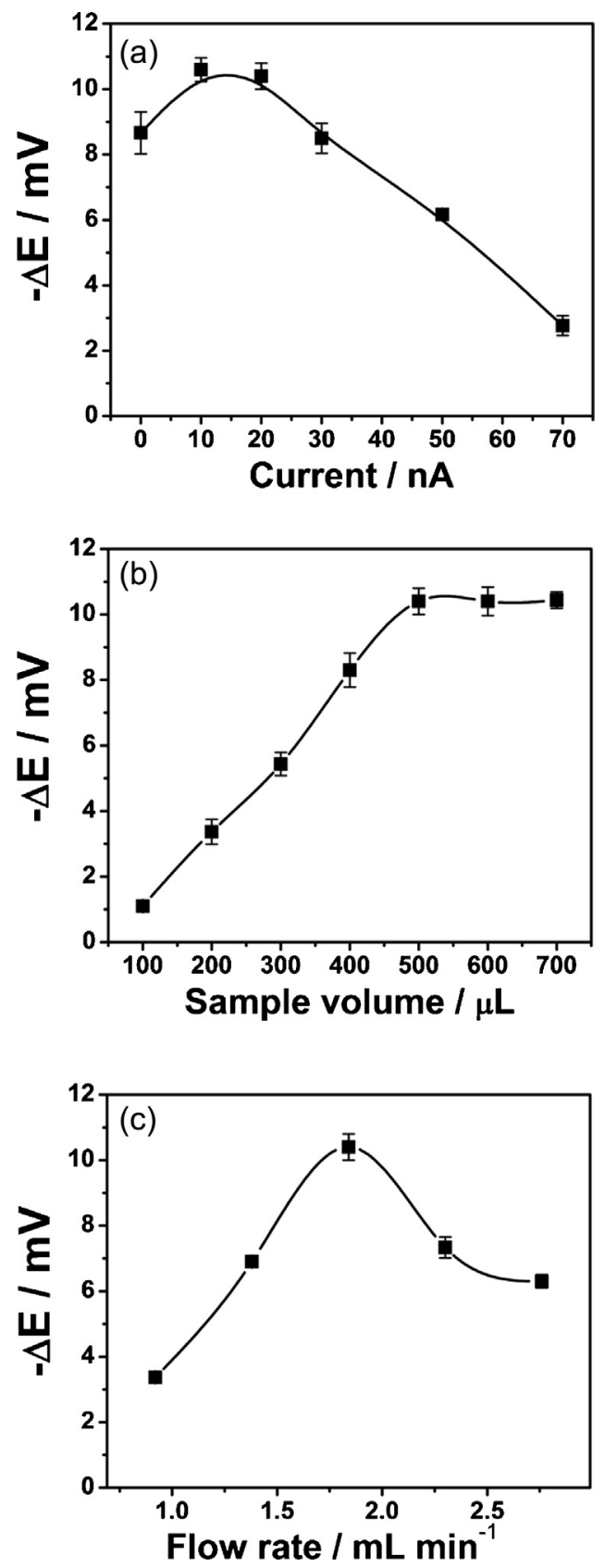

Fig. 3. Effects of the applied current (a), sample volume (b) and flow rate (c) on the potential response to $1.0 \mathrm{U} \mathrm{mL}^{-1}$ heparin in the FIA system. The other conditions are as given in Fig. 2. Each error bar represents one standard deviation for three measurements. (within 200 s) in the flow system (Fig. 4). Compared with the batch mode [28], the FIA detection strategy demonstrated here is more practical especially for rapid analysis of a large number of samples. As shown in the inset of Fig. 4, there is a linear relationship between the potential peak height and the concentration of heparin in the sample solution in the range of $0.1-2.0 \mathrm{U} \mathrm{mL}^{-1}$ $\left(-\Delta E=10.80 \mathrm{C}-0.84, r=0.9976, \Delta E\right.$ in $\mathrm{mV}, \mathrm{C}$ in $\left.\mathrm{UmL}^{-1}\right)$. The detection limit was calculated to be $0.06 \mathrm{U} \mathrm{mL}^{-1}(3 \sigma)$. A relative standard deviation of $4.2 \%$ could be obtained from multiple measurements of $1.0 \mathrm{U} \mathrm{mL}^{-1}$ heparin $(n=7)$. When not in use, the electrodes were stored in $0.05 \mathrm{M}$ Tris- $\mathrm{HCl}$ buffer ( $\mathrm{pH} 7.4$ ) containing $0.12 \mathrm{M} \mathrm{NaCl}$ and $0.05 \mathrm{mg} \mathrm{mL}^{-1}$ protamine at $4{ }^{\circ} \mathrm{C}$. As illustrated in Fig. S1, the polymeric membrane electrode shows a good stability, and no significant change in potential response is observed over a period of 30 days.

\subsection{Interference study}

The lipophilic anions co-existing in biological samples, such as salicylate $\left(\mathrm{Sal}^{-}\right)$and thiocyanate $\left(\mathrm{SCN}^{-}\right)$, can strongly interfere with the potential response to heparin when using the polyanionsensitive membrane electrodes [22]. This problem can be effectively eliminated by the indirect measurements of heparin via the heparin-protamine interaction using the polycationsensitive membrane electrodes $[20,28]$. For the present flow system, the indirect detection mode was employed, and an external current was continuously applied through the polymeric membrane for controlled release of protamine. As expected, $\mathrm{Sal}^{-}$ and $\mathrm{SCN}^{-}$at concentrations ranging from $10^{-7}$ to $10^{-4} \mathrm{~mol} \mathrm{~L}^{-1}$ showed no significant potential responses on the membrane electrode (Fig. 5). It should be noted that chondroitin sulfate (ChS) and hyaluronic acid (HA) are both polyanions that can electrostatically interact with protamine. Although the electrostatic interaction between protamine and $\mathrm{HA}$ or $\mathrm{ChS}$ is weaker than that between protamine and heparin [8], HA and ChS may interfere with the detection of heparin.

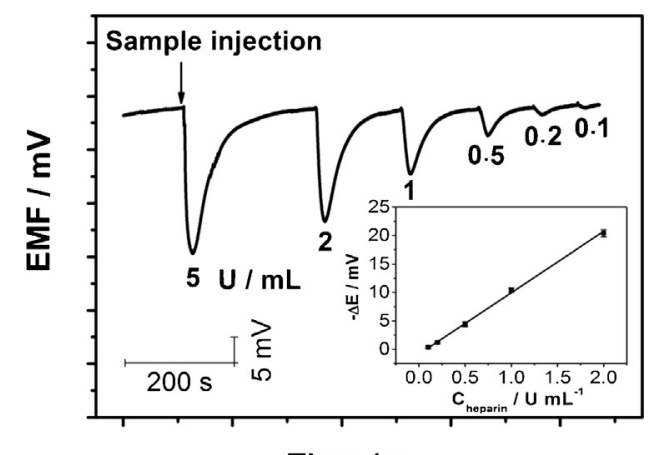

Time / s

Fig. 4. Potential responses to heparin in Tris buffer at different concentrations ranging from 0.1 to $5.0 \mathrm{UmL}^{-1}$. The inset shows the calibration curve for the FIA system. The other conditions are as given in Fig. 2. Each error bar represents one standard deviation for three measurements. 


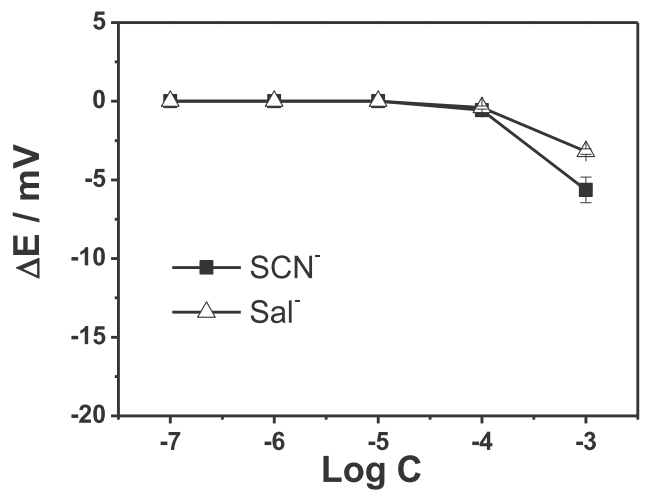

Fig. 5. Potential responses of the polycation-sensitive membrane electrode to interfering ions including $\mathrm{Sal}^{-}$and $\mathrm{SCN}^{-}$at concentrations ranging from $10^{-7}$ to $10^{-3} \mathrm{~mol} \mathrm{~L}^{-1}$. The other conditions are as given in Fig. 2. Each error bar represents one standard deviation for three measurements.

\subsection{Applications}

The proposed FIA detection system was evaluated for determination of heparin in undiluted sheep whole blood, to which citrate ( $\left.0.01 \mathrm{~mol} \mathrm{~L}^{-1}\right)$ was added as the anticoagulant. As shown in Fig. 6, an increase in the membrane potential occurs when the injected undiluted whole blood flows through the surface of the membrane electrode, and notably the first five peaks are above the baseline. Such an effect might be due to the change in sample viscosity. The high viscosity of whole blood could induce large resistance to the mass transport of protamine from the membrane phase to the sample solution, which results in an accumulation of protamine at the membrane surface and thus the increase in the membrane potential. These explanations on the potential responses to the whole blood samples may be confirmed by the diluted blood test. We also investigated the potential responses of the polycationsensitive membrane electrode to heparin in 10-fold diluted pig blood samples at concentrations ranging from 0 to $8.0 \mathrm{U} \mathrm{mL}^{-1}$. In that case, none of the peaks were above the baseline (see Fig. S2). As shown in Fig. 6, the proposed sensing system is useful for measuring heparin in undiluted whole blood in the range of 1$30 \mathrm{UmL}^{-1}\left(-\Delta E=0.40 \mathrm{C}-5.82, r=0.9930, \Delta E\right.$ in $\mathrm{mV}, \mathrm{C}$ in $\left.\mathrm{UmL}^{-1}\right)$ with a detection limit of $0.6 \mathrm{U} \mathrm{mL}^{-1}$. A relative standard deviation of $9.8 \%$ could be obtained for multiple measurements of $5.0 \mathrm{U} \mathrm{mL}^{-1}$ heparin $(n=5)$. Compared with the potential response with buffer solution (Fig. 6), the response to heparin in undiluted whole blood

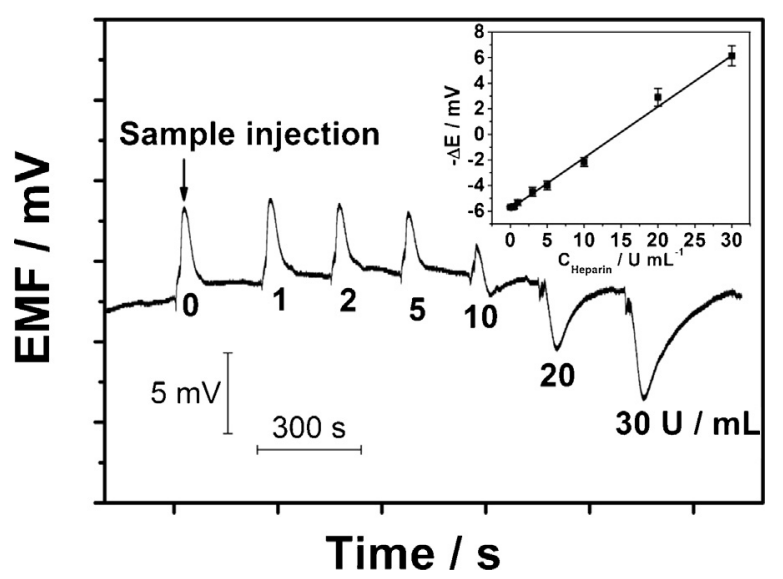

Fig. 6. Potential responses of the polycation-sensitive membrane electrode to heparin in undiluted sheep blood at concentrations ranging from 0 to $40 \mathrm{UmL}^{-1}$. The inset shows the calibration curve. The other conditions are as given in Fig. 2 . Each error bar represents one standard deviation for three measurements. is less pronounced. Indeed, the elevated concentration of protamine at the membrane surface induced by the high viscosity of whole blood makes the membrane electrode insensitive to heparin in the sample solution at lower concentrations. In addition, the electrostatic interaction between protamine and heparin in the viscous medium could be less efficient as compared to that in the buffer solution.

\section{Conclusions}

In summary, a potentiometric flow injection sensing system integrated with a polycation-sensitive membrane electrode has been developed for rapid and continuous determination of heparin based on the current-controlled released of protamine. In contrast to the conventional polyion sensors which are irreversible, the proposed polycation-sensitive membrane electrode can be regenerated rapidly via the current-driven ion fluxes of protamine from the inner filling solution, which allows on-line measurements of heparin in the flow injection mode. The proposed system has been successfully used to determine heparin levels in undiluted sheep whole blood. In addition, the present method can be applied to monitor other species which can interact with protamine, such as aptamers and their targets. Further applications of this sensing configuration are currently in progress in our laboratory.

\section{Acknowledgements}

This work was financially supported by the Instrument Developing Project of the Chinese Academy of Sciences (YZ201161), the National Natural Science Foundation of China (Nos. 41176081,21207156), and the Taishan Scholar Program of Shandong Province.

\section{Appendix A. Supplementary data}

Supplementary data associated with this article can be found, in the online version, at http://dx.doi.org/10.1016/j.aca.2014.12.018.

\section{References}

[1] S.T. Olson, I. Bjork, R. Sheffer, P.A. Craig, J.D. Shore, J. Choay, Role of the antithrombin-binding pentasaccharide in heparin acceleration of antithrombin-proteinase reactions-resolution of antithrombin conformational change contribution to heparin rate enhancement, J. Biol. Chem. 267 (1992) 12528-12538.

[2] G.J. Despotis, G. Gravlee, K. Filos, J. Levy, Anticoagulation monitoring during cardiac surgery - a review of current and emerging techniques, Anesthesiology 91 (1999) 1122-1151.

[3] T.E. Warkentin, M.N. Levine, J. Hirsh, P. Horsewood, R.S. Roberts, M. Gent, J.G. Kelton, Heparin-induced thrombocytopenia in patients treated with lowmolecular-weight heparin or unfractionated heparin, N. Engl. J. Med. 332 (1995) 1330-1335.

[4] B. Girolami, A. Girolami, Heparin-induced thrombocytopenia: a review, Semin. Thromb. Hemost. 32 (2006) 32803-32809.

[5] L.S. Lesserson, G.P. Gravlee, Cardiopulmonary Bypass, in: G.P. Gravee, R.F. Davis, A.F. Stammers, R.M. Ungerleider (Eds.), 3rd ed., Lippincott Williams \& Wilkins, Philadelphia, 2007.

[6] X.L. Fu, L.X. Chen, J.H. Li, M. Lin, H.Y. You, W.H. Wang, Label-free colorimetric sensor for ultrasensitive detection of heparin based on color quenching of gold nanorods by graphene oxide, Biosens. Bioelectron. 34 (2012) 227-231.

[7] A. Khetani, J. Riordon, V. Tiwari, A. Momenpour, M. Godin, H. Anis, Hollow core photonic crystal fiber as a reusable Raman biosensor, Opt. Exp. 21 (2013) $12340-12350$.

[8] X.K. Wang, L. Chen, X.L. Fu, L.X. Chen, Y.J. Ding, Highly sensitive surfaceenhanced Raman scattering sensing of heparin based on anti aggregation of functionalized silver nanoparticles, ACS Appl. Mater. Interfaces 5 (2013) 11059-11065.

[9] F. Galeotti, N. Volpi, Novel reverse-phase ion pair-high performance liquid chromatography separation of heparin, heparan sulfate and low molecular weight-heparins disaccharides and oligosaccharides, J. Chromatogr. A 1284 (2013) 141-147.

[10] J.D. Guo, S. Amemiya, Voltammetric heparin-selective electrode based on thin liquid membrane with conducting polymer-modified solid support, Anal. Chem. 78 (2006) 6893-6902. 
[11] A. Wada, S. Tamaru, M. Ikeda, I. Hamachi, MCM-enzyme-supramolecular hydrogel hybrid as a fluorescence sensing material for polyanions of biological significance, J. Am. Chem. Soc. 131 (2009) 5321-5330.

[12] S.C. Ma, V.C. Yang, M.E. Meyerhoff, Heparin-responsive electrochemical sensor: a priliminary-study, Anal. Chem. 64 (1992) 694-697.

[13] B. Fu, E. Bakker, J.H. Yun, V.C. Yang, M.E. Meyerhoff, Response mechanism of polymer membrane-based potentiometric polyion sensors, Anal. Chem. 66 (1994) 2250-2259.

[14] B. Fu, E. Bakker, J.H. Yun, E.J. Wang, V.C. Yang, M.E. Meyerhoff, Polymer membrane-based polyion sensors-development, response mechanism, and bioanalytical applications, Electroanalysis 7 (1995) 823-829.

[15] M.E. Meyerhoff, V.C. Yang, J.A. Wahr, J.H. Yun, B. Fu, E. Bakker, Potentiometric polyion sensors: new measurement technology for monitoring blood heparin concentrations during open-heart-surgery, Clin. Chem. 41 (1995) 1355-1355.

[16] N. Baliga, N. Ramamurthy, M.E. Meyerhoff, V.C. Yang, J.A. Wahr, A novel protamine sensor for measurement of heparin levels in blood and plasma, Anesth. Analg. 86 (1998) Sca26.

[17] N. Baliga, V.C. Yang, M.E. Meyerhoff, Protamine-sensitive polymer membrane electrodes for the determination of heparin and low-molecular weight heparin in whole blood, Clin. Chem. 44 (1998) A52-A53.

[18] N. Ramamurthy, N. Baliga, J.A. Wahr, U. Schaller, V.C. Yang, M.E. Meyerhoff, Improved protamine-sensitive membrane electrode for monitoring heparin concentrations in whole blood via protamine titration, Clin. Chem. 44 (1998) 606-613.

[19] Q.S. Ye, M.E. Meyerhoff, Rotating electrode potentiometry: lowering the detection limits of nonequilibrium polyion-sensitive membrane electrodes Anal. Chem. 73 (2001) 332-336.

[20] W. Qin, W. Zhang, K.P. Xiao, M.E. Meyerhoff, Enhanced sensitivity electrochemical assay of low-molecular-weight heparins using rotating polyion-sensitive membrane electrodes, Anal. Bioanal. Chem. 377 (2003) 929-936.

[21] B. Fu, E. Bakker, V.C. Yang, M.E. Meyerhoff, Extraction thermodynamics of polyanions into plasticized polymer membranes doped with lipopphilic ionexchangers: a potentiometric study, Macromolecules 28 (1995) 5834-5840.

[22] K.L. Gemene, M.E. Meyerhoff, Reversible detection of heparin and othe polyanions by pulsed chronopotentiometric polymer membrane electrode, Anal. Chem. 82 (2010) 1612-1615.
[23] A. Shvarev, E. Bakker, Reversible electrochemical detection of nonelectroactive polyions, J. Am. Chem. Soc. 125 (2003) 11192-11193.

[24] A. Shvarev, E. Bakker, Response characteristics of a reversible electrochemical sensor for the polyion protamine, Anal. Chem. 77 (2005) 5221-5228.

[25] K.L. Gemene, E. Bakker, Flash chronopotentiometric sensing of the polyions protamine and heparin at ion-selective membranes, Anal. Biochem. 386 (2009) 276-281.

[26] G.A. Crespo, M.G. Afshar, E. Bakker, Reversible sensing of the anticoagulant heparin with protamine permselective membranes, Angew. Chem. Int. Ed. 51 (2012) 12575-12578.

[27] A.K. Bell-Vlasov, J. Zajda, A. Eldourghamy, E. Malinowska, M.E. Meyerhoff, Polyion selective polymeric membrane-based pulstrode as a detector in flowinjection analysis, Anal. Chem. 86 (2014) 4041-4046.

[28] Y. Chen, J.W. Ding, W. Qin, Polycation-sensitive membrane electrode for determination of heparin based on controlled release of protamine, Analyst 137 (2012) 1944-1949.

[29] J.X. Lei, J.W. Ding, W. Qin, Flow injection biosensor for detection of ATP based on polyion-sensitive membrane electrode, Chem. Bioeng. 31 (2014) 71-765 (in Chinese).

[30] J.W. Ding, W. Qin, Current-driven ion fluxes of polymeric membrane ionselective electrode for potentiometric biosensing, J. Am. Chem. Soc. 131 (2009) $14640-14641$.

[31] J.W. Ding, Y. Chen, X.W. Wang, W. Qin, Label-free and substrate-free potentiometric aptasensing using polycation-sensitive membrane electrodes, Anal. Chem. 84 (2012) 2055-2061.

[32] W.J. Song, J.W. Ding, R.N. Liang, W. Qin, Potentiometric flow injection system for determination of reductants using a polymeric membrane permanganate ion-selective electrode based on current-controlled reagent delivery, Anal. Chim. Acta 704 (2011) 68-72.

[33] V. Bhakthavatsalam, A. Shvarev, E. Bakker, Selective coulometric release of ions from ion selective polymeric membranes for calibration-free titrations, Analyst 131 (2006) 895-900.

[34] G.A. Crespo, M.G. Afshar, D. Dorokhin, E. Bakker, Thin layer coulometry based on ion-exchanger membranes for heparin detection in undiluted human blood, Anal. Chem. 86 (2014) 1357-1360. 